\title{
Stable expression of the oxc and frc genes from Oxalobacter formigenes in human embryo kidney 293 cells: Implications for gene therapy of hyperoxaluria
}

\author{
ZHANG-QUN YE* , DE-BO KONG* ${ }^{*}$ ZHI-QIANG CHEN, LIN-FANG YAO, HUI GUO, \\ XIAO YU, GUAN-LIN LIU and WEI-MIN YANG \\ Department of Urology, Tongji Hospital, Tongji Medical School, \\ Huazhong University of Science and Technology, Wuhan, Hubei 430030, P.R. China
}

Received April 10,2007; Accepted May 24, 2007

\begin{abstract}
Hyperoxaluria can lead to multiple pathologic conditions such as recurrent urolithiasis, oxalosis, nephrocalcinosis and even renal failure, but there is no known oxalate-degrading pathway in the human body, and current therapeutic options for patients with hyperoxaluria are limited. Oxalyl-CoA decarboxylase and formyl-CoA transferase are the key enzymes in the oxalate catabolism of Oxalobacter formigenes which dwell in the intestine of vertebrates and have an important symbiotic relationship with their hosts. The aim of this study was to insert the oxalate-degrading enzyme genes into human embryo kidney (HEK) 293 cells and to evaluate if the oxalate-degrading enzymes could be expressed in these cells and keep their enzyme activity. We present here the cloning of the two genes from $O$.formigenes and their subsequent expression in HEK293 cells. The results showed that the expression of oxalyl-CoA decarboxylase and formyl-CoA transferase was confirmed by RT-PCR and Western blotting, and the proteins were located in the cytoplasm of transfected cells. Furthermore, the transfected cells were capable to a certain degree of degrading oxalate. These findings suggest that the transfer of oxalate-degrading enzyme genes into human cells is possibly a potential candidate for the gene therapy of hyperoxaluria.
\end{abstract}

\section{Introduction}

Oxalate is a highly toxic natural by-product of normal cellular metabolism and is ingested with many common foods and

Correspondence to: Professor Zhi-Qiang Chen, Department of Urology, Tongji Hospital, Tongji Medical School, Huazhong University of Science and Technology, 1095 Jiefang Ave., Wuhan, Hubei 430030, P.R. China

E-mail: zhqchen8366@163.com

\section{${ }^{*}$ Contributed equally}

Key words: Oxalobacter formigenes, hyperoxaluria, urolithiasis, gene therapy, oxalyl-CoA decarboxylase, formyl-CoA transferase beverages such as tea, coffee, chocolate, fruits, and vegetables (1). There are several distinct mechanisms for oxalate catabolism present in nature, but unfortunately no oxalatedegrading pathway has been found in the human body. The abnormal synthesis of oxalate, mainly in the liver, or hyperabsorption in the gut can lead to the accumulation of oxalate in vivo and can result in a disorder in oxalate metabolism, hyperoxaluria. Hyperoxaluria can bring about multiple pathologic conditions such as recurrent urolithiasis, oxalosis, nephrocalcinosis and even early renal failure (2). In patients with hyperoxaluria, current therapeutic options are limited and do not always lead to adequate success towards sufficiently decreasing the oxalate synthesis in the liver and reducing the oxalate excretion through the urinary system.

Recent evidence suggests that oxalate-degrading microorganisms dwelling in the gut, in particular Oxalobacter formigenes, have an important symbiotic relationship with their hosts by degrading oxalate and regulating oxalate absorption in the intestine (3). The absence of $O$. formigenes is believed to increase the risk of recurrent calcium oxalate stones (4). O. formigenes is a group of obligate anaerobic bacterium utilizing oxalate as its exclusive source of energy, which was characterized and first named by Allison et al in 1985 (5). Initially, O. formigenes were isolated from the rumen (6), the large bowel of herbivores (7), freshwater lake sediments (8), and human feces (5). They are similar in that they are all gram-negative, obligately anaerobic, nonmotile, rod-shaped, but are different in cellular fatty acid composition and serologic reaction, by which they are divided into several groups and strains (5).

Oxalyl-CoA decarboxylase (OXC) and formyl-CoA transferase (FRC), which are encoded by the oxc and frc genes, are key enzymes in the oxalate metabolism of $O$. formigenes and were first purified by Baetz and Allison in 1989 (9) and 1990 (10), respectively. Oxalate can be metabolized to produce $\mathrm{CO}_{2}$ and formate in a two-step enzymatic reaction catalyzed by OXC and FRC (11). If human cells can gain the capacity of oxalate metabolism by the transgene of $o x c$ and frc, there will be a promising new therapy option for hyperoxaluria. But $o x c$ and $f r c$ are prokaryotic genes generally expressed in bacteria, and it is yet uncertain whether the $o x c$ and $f r c$ genes can be expressed in 
eukaryocytes and still reserve the oxalate-degrading enzyme activity. In the present study, we constructed eukaryotic expression vectors containing the coding sequence of the oxc or frc genes labeled by an EGFP gene, and we stably transfected human embryo kidney 293 cells (HEK293) with these vectors. Moreover, the expression and enzyme activity of OXC and FRC in HEK293 cells were determined by a series of assays.

\section{Materials and methods}

Bacteria. The strain was isolated from fecal samples of healthy Chinese (data not shown). The anaerobic culture methods described by Allison (5) and Dawson (6) were employed. The strain was named $O x C F$ and kept at the urologic laboratory of Tongji hospital at $-80^{\circ} \mathrm{C}$.

PCR for oxc and frc genes. The genomic DNA, as a template for following PCR amplification, was extracted from $O x C F$ cells using a Takara bacterial genomic DNA extraction kit (Takara, Dalian, P.R. China). According to the nucleotide sequence of the $o x c$ and frc genes which were sequenced in our previous work, two pairs of oligonucleotide primers were synthesized as follows: the oxc gene, forward primer (5' GG AATTCGATGAGTAACGACGAC 3') reverse primer (5' C GGGATCCAATTTCTTGCCAACT 3 '); and the frc gene, forward primer (5' CGGAATTCGATGACTAAACCAT 3'), reverse primer (5' CGGGATCCGAAACTACCTGTTT 3'). $E c o$ RI and $B a m \mathrm{HI}$ restriction sites were incorporated into the $5^{\prime}$ end of the forward and reverse primers, respectively. PCR was carried out for one cycle at $95^{\circ} \mathrm{C}$ for $5 \mathrm{~min}$, followed by 35 cycles of $30 \mathrm{sec}$ at $95^{\circ} \mathrm{C}, 30 \mathrm{sec}$ at $55^{\circ} \mathrm{C}$, and $60 \mathrm{sec}$ at $72^{\circ} \mathrm{C}$ and another $10 \mathrm{~min}$ at $72^{\circ} \mathrm{C}$ for extension. The products were electrophoresed in $1 \%$ agarose gel for documentation.

Construction of eukaryotic expression vector. The eukaryotic expression vector pEGFP-N1 (Clontech, USA) was employed to subclone the genes of interest. The plasmids and PCR products were digested with EcoRI and BamHI restriction enzymes and then size separated by electrophoresis. Separated DNA fragments of pEGFP $(4.7 \mathrm{~kb})$, oxc $(1.7 \mathrm{~kb})$ and $f r c(1.3 \mathrm{~kb})$ were extracted from gel slices and then ligated overnight respectively. Recombinant plasmids were identified by EcoRI and BamHI restriction enzyme digestion and DNA sequencing. The successfully constructed expression vectors were named pEGFP-oxc and pEGFP-frc.

Gene transfer and cell culture. HEK293 cells (ATCC, USA) were employed to express the oxc and frc genes transferred by lipofection. HEK293 cells were seeded onto 24-well plates at a density of $1 \times 10^{5}$ cells per well. After $24 \mathrm{~h}$ of incubation, transfection was performed by Lipofectamine ${ }^{\mathrm{TM}}$ 2000 (Invitrogen, USA) according to the manufacturer's instructions. Plasmids $(0.8 \mu \mathrm{g})$ (pEGFP-oxc, pEGFP-frc or pEGFP) and $2.0 \mu \mathrm{l}$ liposome were involved in the procedure of lipofection for one well. After $48 \mathrm{~h}$ of culture, the transfected HEK293 cells were cultured with $800 \mu \mathrm{g} / \mathrm{ml}$ G418 (Gibco, USA) for 2 weeks and then $400 \mu \mathrm{g} / \mathrm{ml}$ for 3 weeks. Green fluorescence was observed under a fluorescence inverted microscope, and the percentage of EGFP-positive cells detected at $48 \mathrm{~h}$ reflected the transfection efficiency of the cells.

$R T$-PCR analysis. Total RNA $(2 \mu \mathrm{g})$ was applied to synthesize cDNA by a one-step RT-PCR kit (Promega, USA) according to the manufacturer's instructions, and then $1 \mu \mathrm{l}$ cDNA was used as the template for subsequent PCR amplification. After $5 \mathrm{~min}$ at $95^{\circ} \mathrm{C}, 30$ cycles of PCR with parameters of $95^{\circ} \mathrm{C}$ for $30 \mathrm{sec}, 50^{\circ} \mathrm{C}$ for $30 \mathrm{sec}$, and $72^{\circ} \mathrm{C}$ for $60 \mathrm{sec}$, followed by a final extension at $72^{\circ} \mathrm{C}$ for $10 \mathrm{~min}$, was performed to amplify cDNA of $\beta$-actin, oxc and frc genes. Three pairs of oligonucleotide primers were synthesized as follows: $\beta$-actin, forward primer (5' GCGGCTACAGCTT CACCACCA 3'), reverse primer (5' CGCCGATCCACACG GAGTACT 3'); the oxc gene, forward primer (5' GGCCAG ACCATTTCCGTAGAA 3'), reverse primer (5' TGCTGCA TCAGCCAGTTCAGA 3'); and the frc gene, forward primer (5' GCACTGGACCGTATGGGCTTT 3'), reverse primer (5' CGGTTTTGTGACGCATTTCCA 3'). The PCR products were 441,347 and $271 \mathrm{bp}$, respectively.

Western blot analysis. The total proteins $(50 \mu \mathrm{g})$ harvested from each sample were subjected to a $10 \%$ SDS-PAGE gel electrophoresis for $2 \mathrm{~h}$ and then electrotransferred to a nitrocellulose membrane. Blocked with 5\% skimmed milk for $1 \mathrm{~h}$, the membrane was probed with a primary rabbit polyclonal antibody against EGFP (1:100, sc-8334, Santa Cruz, USA) and a primary rabbit polyclonal antibody against human $\beta$-actin (1:500, sc-1616-R, Santa Cruz) and diluted in TBST overnight at $4^{\circ} \mathrm{C}$. After being washed three times for $10 \mathrm{~min}$ each, the membrane was incubated with horseradish peroxidase-conjugated secondary antibody for $1 \mathrm{~h}$ at $37^{\circ} \mathrm{C}$. After being washed again, it was reacted with enhanced chemiluminescence reagent (Pierce, USA), wrapped with film and exposed.

Transfer of CoA. The enzyme activity of recombinant FRC was estimated by determining the change of oxalate concentration in the medium. Formyl-CoA was prepared by previously described procedures (12). Sodium oxalate (Sigma-Aldrich, USA) and formyl-CoA were dissolved in PBS and filtered to sterilize, respectively. HEK293, HEK293/ pEGFP-frc and HEK293/pEGFP cells were seeded onto 7 wells in 24-well plates at a density of $5 \times 10^{4}$ cells per well respectively. After $48 \mathrm{~h}$ of culture at $37^{\circ} \mathrm{C}$, the medium was replaced with DMEM supplemented with $100 \mu \mathrm{mol} / 1$ sodium oxalate and $200 \mu \mathrm{mol} / 1$ formyl-CoA. The latter was collected at different time points $(0,3,6,9,12,15,18,21$, and $24 \mathrm{~h})$ and filtered by a $0.2-\mu \mathrm{m}$ membrane. Then the filtrate was injected into a DX-80 ion chromatograph (Dionex, USA) to determine the concentration of oxalate or a Symmetry $\mathrm{C}_{18}$ analytical column $(3.9 \times 150 \mathrm{~mm}, 5 \mu \mathrm{m})$ to measure the concentration of oxalyl-CoA.

Decarboxylation of oxalyl-CoA. The enzyme activity of recombinant $\mathrm{OXC}$ was estimated by determining the change in oxalyl-CoA concentration in the medium. Oxalyl-CoA was prepared by previously described procedures $(12,13)$ and dissolved in PBS. Then the solution was filtered to sterilize and added to DMEM. HEK293, HEK293/pEGFP-oxc and 


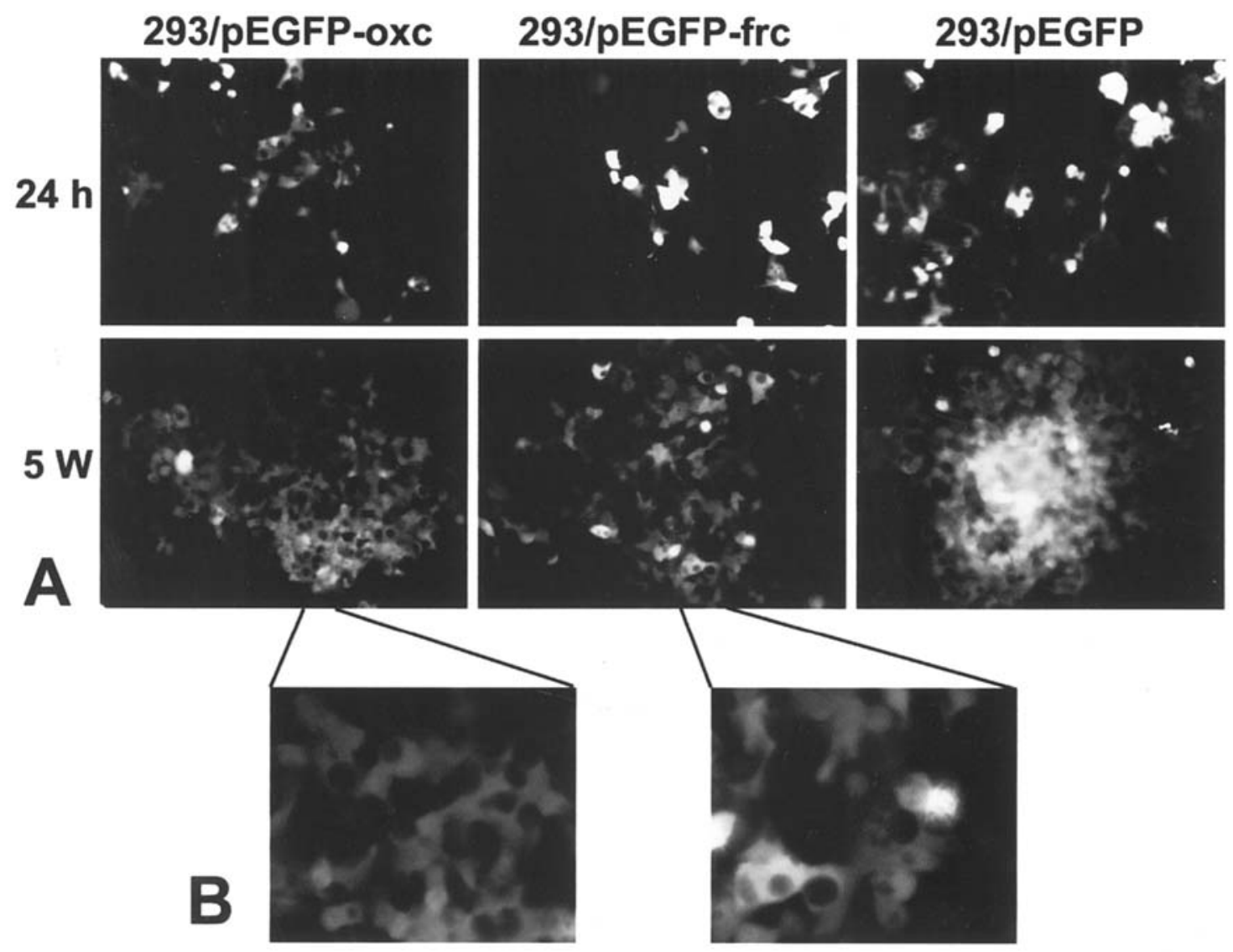

Figure 1. The transfected cells identified by green fluorescence. At $48 \mathrm{~h}$ after transfection, the transfection efficiency of pEGFP-oxc, pEGFP-frc and control plasmids was $23.5,21.3$ and $35.7 \%$, respectively (A). At 5 weeks after transfection, almost all cells exhibited bright green fluorescence (A) and fusion proteins were located in the cytoplasm (B).

HEK293/pEGFP cells were seeded into 7 wells in 24-well plates at a density of $5 \times 10^{4}$ cells per well respectively. After $48 \mathrm{~h}$, the medium was replaced with DMEM containing $100 \mu \mathrm{mol} / 1$ oxalyl-CoA and then the latter was collected at different time points $(0,3,6,9,12,15,18,21$, and $24 \mathrm{~h})$. Subsequently, $200 \mu \mathrm{l}$ of the fluid was passed through a $0.2-\mu \mathrm{m}$-pore-size filter and injected onto a Symmetry $\mathrm{C}_{18}$ analytical column $(3.9 \times 150 \mathrm{~mm}, 5 \mu \mathrm{m})$ to determine the concentration of oxalyl-CoA by a reverse-phase highperformance liquid chromatograph (Waters, USA) using a modified procedure for analyzing CoA derivatives $(12,14)$.

Statistical analysis. All experiments were repeated 5 times. The statistical software package SPSS 12.0 was used to analyze the data. The $\chi^{2}$ test was performed to compare frequencies among the groups. $\mathrm{P}$ values $<0.05$ were considered statistically significant.

\section{Results}

Stable transfection with pEGFP-oxc and pEGFP-frc in the HEK293 cells. pEGFP-oxc, pEGFP-frc and control plasmids were transferred into HEK293 cells by lipofection followed by selective culture respectively. Six hours after transfection, slight green fluorescence was visible in these cells using 488-nm blue laser excitation light under a fluorescence inverted microscope. The cells were grown for 2 days in non-

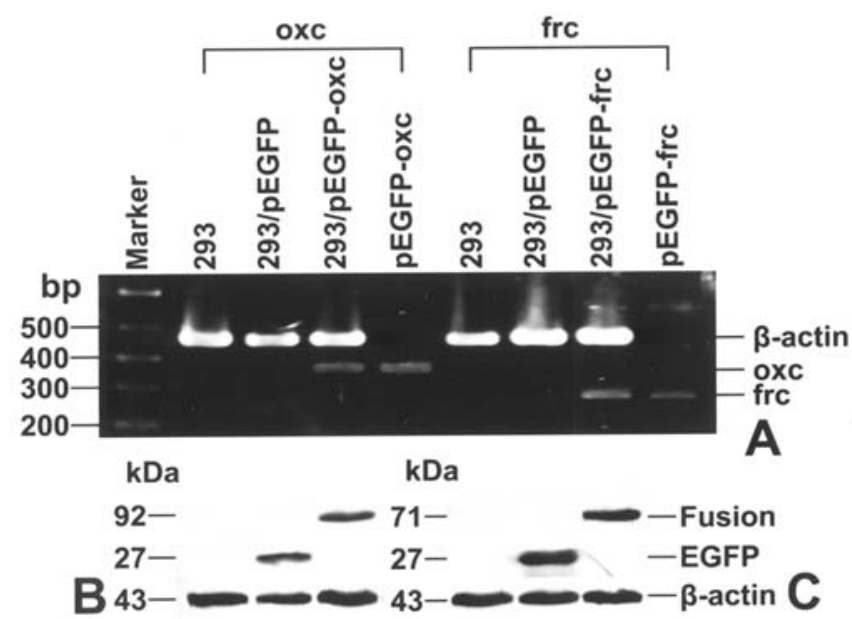

Figure 2. Expression of the recombinant $o x c$ and frc genes. The sizes of PCR-amplified fragments were equal to those of the positive controls directly amplified from recombinant vectors (A). The results of protein immunoblot analysis showed that fusion protein OXC (B) or FRC (C) was detected in the stably transfected cells.

selective medium and then trypsinized followed by seeding into 6-well plates under a selective pressure of $800 \mu \mathrm{g} / \mathrm{ml}$ G418. At 24 and $48 \mathrm{~h}$ after transfection, bright green fluorescence was observed from a few cells scattered throughout the wells, and the transfection efficiency at $48 \mathrm{~h}$ of pEGFP- 


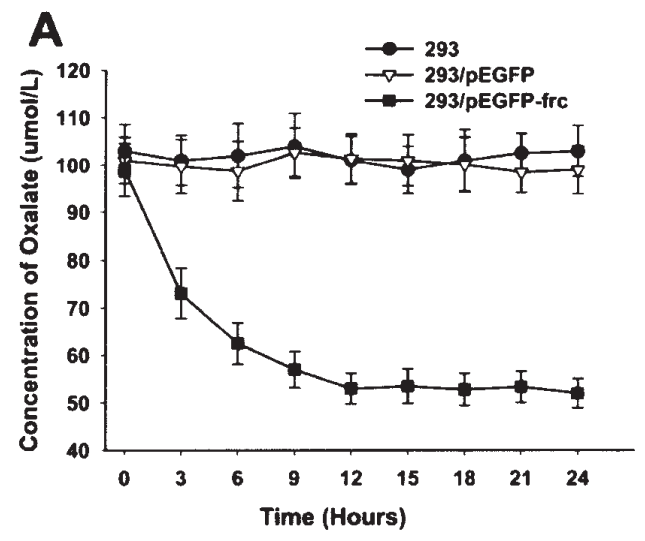

B
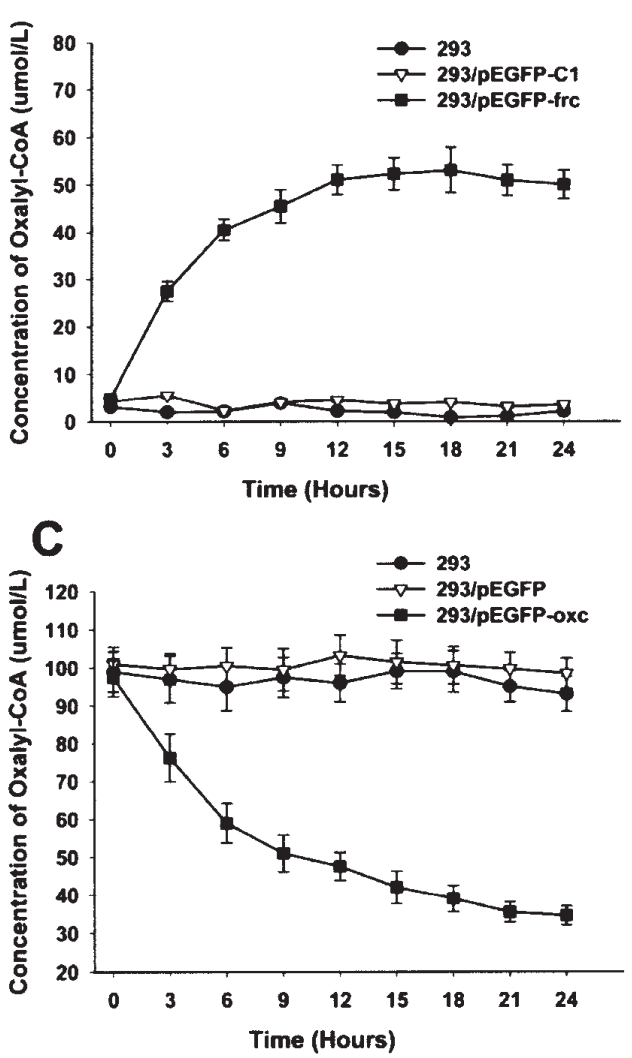

Figure 3 . The change in oxalate and oxalyl-CoA concentration in the medium of stably transfected HEK293 cells. The results of an ion chromatograph and a reverse-phase high-performance liquid chromatograph exhibited a prominent decrease in the oxalate concentration (A) and a corresponding increase of the oxalyl-CoA concentration (B) in the medium of HEK293 cells transfected with pEGFP-frc. In the medium of HEK293 cells transfected with pEGFP-oxc, there exhibited a significant reduction in the oxalyl-CoA concentration (C).

oxc, pEGFP-frc and the control plasmids was 23.5, 21.3 and $35.7 \%$, respectively. After 3 days of G418-selective culture, several fluorescent cell colonies formed and a few nonfluorescent cells were scattered in the colonies. To achieve a pure and stably transfected cell line, the single colonies of cells were picked out and seeded again at a diluted density every 3 days for 2 weeks. Subsequently, selected cells were proliferated under a selective pressure of $400 \mu \mathrm{g} / \mathrm{ml} \mathrm{G} 418$ for 3 weeks. At this time almost all cells exhibited bright green fluorescence as shown in Fig. 1A.
Localization and expression of the recombinant oxc and frc genes in the transfected HEK293 cells. In the stably transfected HEK293 cells, the results reported by green fluorescence showed that the fusion proteins were located in the cytoplasm (Fig. 1B). RT-PCR and Western blotting were performed to confirm the expression of the recombinant oxc and frc genes. Compared with the HEK293 cells transfected with the control plasmids, certain oxc or frc mRNA expression in HEK293 cells transfected with pEGFP-oxc or pEGFP-frc was demonstrated by RT-PCR respectively (Fig. 2A). The sizes of amplified fragments were equal to those of the positive controls directly amplified from recombinant vectors. Protein immunoblot analysis was performed with an anti-EGFP monoclonal antibody. As shown in Fig. 2B and C, expression of EGFP (27 kDa) and fusion protein OXC (92 kDa) or FRC $(71 \mathrm{kDa})$ was detected in cells transfected with control plasmids pEGFP-oxc and pEGFP-frc, respectively.

The transfer of CoA from formyl-CoA to oxalate by the cells transfected with pEGFP-frc. To confirm if the FRC expressed in the HEK293 cells retained its enzyme activity capable of transferring CoA from formyl-CoA to oxalate, the concentration of oxalate and oxalyl-CoA in the medium was detected for $24 \mathrm{~h}$. As shown in Fig. 3A and B, the concentration of oxalate in the medium of HEK293 cells transfected with pEGFP-frc exhibited a prominent decrease, and the concentration of oxalyl-CoA exhibited a corresponding increase, but there was no significant shift observed in the medium of HEK293 and HEK293/pEGFP cells.

The decarboxylation of oxalyl-CoA by the cells transfected with pEGFP-oxc. The decarboxylation of oxalyl-CoA to formyl-CoA was catalyzed by $\mathrm{OXC}$ of $O$. formigenes, but it was uncertain whether the recombinant OXC expressed in the HEK293 cells retained its enzyme activity. An assay was designed to identify the activity of recombinant $\mathrm{OXC}$ by measuring the concentration of oxalyl-CoA throughout a 24-h culture period by a reverse-phase high-performance liquid chromatograph. Results shown in Fig. 3C confirmed a significant decrease of oxalyl-CoA in the medium of HEK293 cells transfected with pEGFP-oxc.

\section{Discussion}

In the 1980 's, O.formigenes, an oxalate-degrading bacterium dwelling in the gut of humans and herbivores, was identified by Allison et al $(5,7,15)$. O. formigenes is a group of gramnegative, obligately anaerobic, nonmotile, rod-shaped bacteria dwelling especially in the colon and considered absolutely dependent on oxalate metabolism for energy. Many researchers believe that $O$. formigenes may play an important role in regulating dietary oxalate absorption of the digestive system and are closely related to urinary stone formation in humans (15-17). Because they are abundant in the normal human colon $\left(10^{7}\right.$ per gram feces) and rates of oxalate degradation by feces range from $0.1-4.8 \mathrm{nmol} /(\mathrm{g} \mathrm{x} \mathrm{h})(15), O$. formigenes may digest enough oxalate to reduce intestinal absorption and corresponding urinary excretion of oxalate. It has been suggested that $O$. formigenes have an important symbiotic relationship with their hosts by degrading oxalate and 
regulating oxalate absorption in the intestine $(3,18)$. Further studies indicated that there were less $O$. formigenes detected in the feces of calcium oxalate stone patients than that of normal individuals, and lack of $O$. formigenes might be an important risk factor for urinary stone formation $(19,20)$. In addition, $O$. formigenes is probably antibiotic sensitive, and repeated antibiotic therapies could eradicate it. Thus the use of antibiotics may contribute to the loss of $O$. formigenes $(16,21)$.

The decarboxylated degradation of oxalate in $O$. formigenes is a two-step enzymatic reaction catalyzed by OXC and FRC transferase $(9,10)$. In this anaerobic metabolic procedure, one molecule of oxalate is decarboxylated to form one molecule of $\mathrm{CO}_{2}$ and one molecule of formate, which is coupled with ATP synthesis (22). FRC is encoded by the frc gene and catalyzes a transfer of CoA from formate to oxalate (10), which is necessary for the activation of oxalate before its decarboxylation, while OXC is encoded by the oxc gene and mediates an oxalyl moiety for thiamine-dependent decarboxylation to form formyl-CoA and liberate $\mathrm{CO}_{2}$ (9). The recombinant genes of the two key enzymes were heterologously expressed in Escherichia coli, and the products exhibited enzyme activity similar to the native enzymes (23-25).

$\mathrm{OXC}$ and FRC expressed in a foreign environment retain their oxalate-degrading enzyme activity. Therefore, if the two key enzymes can retain their enzyme activity in mammalian cells, especially in human cells, there will exist a promising new therapy option for hyperoxaluria by transferring oxalatedegrading enzyme genes from $O$. formigenes into patients. Such studies were initiated by Lung et al in 1991 (23), but much further research is still required such as determining if the oxalate-degrading enzyme genes can be transferred into human cells and retain their enzyme activity in vitro. In this study, we presented the cloning of the OXC and FRC genes of $O$.formigenes and their subsequent expression in HEK293 cells.

In our study, a eukaryotic expression vector pEGFP-N1 was employed to subclone the frc and $o x c$ genes, respectively. pEGFP is a common vector for eukaryotic expression of exogenous genes and encodes enhanced green fluorescent protein (EGFP), a mutant of wild-type GFP, which has been optimized for brighter fluorescence and higher expression in mammalian cells (26). EGFP is considered a rapid and sensitive reporter gene as a biological marker and the proteins which fuse to the N-terminus of EGFP gain fluorescent property while always retaining their native function (27). We amplified the oxc and frc genes from genomic DNA extracted from $\mathrm{OxCF}$, an $O$. formigenes strain, from the fecal samples of healthy Chinese and then inserted the gene fragments into pEGFP respectively. Subsequently, the recombinant plasmids which carried the oxc or frc gene as fusion to the N-terminus of EGFP were transferred to HEK293 cells by lipofection respectively. At $48 \mathrm{~h}$ after transfection, the transfection efficiency of pEGFPoxc and pEGFP-frc reported by green fluorescence was 23.5 and $21.3 \%$, compared with $35.7 \%$ of the control plasmids. After 5 weeks of G418-selective culture, almost all cells exhibited bright green fluorescence, which indicated stable transfection and expression of the three plasmids.
In most cases the resultant chimera of EGFP and the tagged protein does not affect the activity of the latter (27). Another purpose of EGFP in this study included its use as fusion tags of OXC and FRC. The fluorescence of HEK293 cells transfected with pEGFP-oxc or pEGFP-frc showed that the fusion proteins were located in the cytoplasm. Since there is no commercial antibody of OXC and FRC, we applied an antibody against EGFP to perform the Western blot analysis of the fusion proteins. In some previous studies $(9,10)$, the SDS-PAGE gel electrophoresis of FRC and OXC indicated their molecular weights of 44 and $65 \mathrm{kDa}$. Correspondingly, the molecular weights of the EGFP $(27 \mathrm{kDa})$ fusion proteins are $\sim 71$ and $92 \mathrm{kDa}$. In this study, the total proteins of stably transfected HEK293 cells were subjected to a $10 \%$ SDSPAGE gel electrophoresis and the results showed apparent bands corresponding to the predicted size of fusion proteins. Analysis of RT-PCR products by agarose gel electrophoresis further confirmed the expression of the recombinant $o x c$ and frc genes in the stably transfected HEK293 cells.

Previous studies (23-25) showed heterologous expression of FRC and OXC in Escherichia coli. But it was still uncertain whether the FRC and OXC could retain their enzyme activity as exogenous proteins in human cells. There are several examples of the expression of prokaryotic genes in eukaryotes such as the LacZ (28) and G418-resistance genes (29). The optima of FRC and OXC activity $\left(37^{\circ} \mathrm{C}, \mathrm{pH}\right.$ 6.5 to 7.5 ) (10) is similar to the homeostasis of the human. In this study, the change of oxalate and oxalyl-CoA concentration in the medium was documented for $24 \mathrm{~h}$ to ascertain whether the FRC and OXC recombinantly expressed in the HEK293 cells retained their enzyme activity capable of transferring CoA from formyl-CoA to oxalate or decarboxylate oxalyl-CoA to formyl-CoA. The results showed that the concentration of oxalate in the medium of HEK293 cells transfected with pEGFP-frc exhibiting a prominent decrease, and the concentration of oxalyl-CoA exhibited a corresponding increase, which indicated oxalate could be activated to oxalyl-CoA by recombinant FRC. In the medium of HEK293 cells transfected with pEGFP-oxc, there was a significant decrease in oxalyl-CoA, which indicated that oxalyl-CoA could be decarboxylated to formyl-CoA by recombinant OXC.

Accumulation of oxalate can result in hyperoxaluria, and severe hyperoxaluria always leads to oxalosis, nephrocalcinosis, recurrent urolithiasis, and even early renal failure (2). As treatment options for patients with hyperoxaluria especially primary hyperoxaluria are limited, new therapeutic approaches are still needed for these patients. This study provides evidence that recombinant OXC and FRC can be expressed in human cells and can keep their oxalatedegrading enzyme activity, which implies a potential candidate for the gene therapy of hyperoxaluria. However, further studies, such as experiments based on animal models in vivo, are clearly needed.

\section{Acknowledgements}

This study was supported by grants from the National Science Foundation of P.R. China (nos. 30371423, 30670820). 


\section{References}

1. James LF: Oxalate toxicosis. Clin Toxicol 5: 231-243, 1972.

2. Leumann E and Hoppe B: The primary hyperoxalurias. J Am Soc Nephrol 12: 1986-1993, 2001.

3. Cornelius JG and Peck AB: Colonization of the neonatal rat intestinal tract from environmental exposure to the anaerobic bacterium Oxalobacter formigenes. J Med Microbiol 53: 249-254, 2004.

4. Kumar R, Mukherjee M, Bhandari M, Kumar A, Sidhu H and Mittal RD: Role of Oxalobacter formigenes in calcium oxalate stone disease: a study from North India. Eur Urol 41: 318-322, 2002.

5. Allison MJ, Dawson KA, Mayberry WR and Foss JG: Oxalobacter formigenes gen. nov., sp. nov.: oxalate-degrading anaerobes that inhabit the gastrointestinal tract. Arch Microbiol 141: 1-7, 1985 .

6. Dawson KA, Allison MJ and Hartman PA: Isolation and some characteristics of anaerobic oxalate-degrading bacteria from the rumen. Appl Environ Microbiol 40: 833-839, 1980.

7. Allison MJ and Cook HM: Oxalate degradation by microbes of the large bowel of herbivores: the effect of dietary oxalate. Science 212: 675-676, 1981.

8. Smith RL, Strohmaier FE and Oremland RS: Isolation of anaerobic oxalate-degrading bacteria from freshwater lake sediments. Arch Microbiol 141: 8-13, 1985.

9. Baetz AL and Allison MJ: Purification and characterization of oxalyl-coenzyme A decarboxylase from Oxalobacter formigenes. J Bacteriol 171: 2605-2608, 1989.

10. Baetz AL and Allison MJ: Purification and characterization of formyl-coenzyme A transferase from Oxalobacter formigenes. J Bacteriol 172: 3537-3540, 1990.

11. Ricagno S, Jonsson S, Richards N and Lindqvist Y: Formyl$\mathrm{CoA}$ transferase encloses the $\mathrm{CoA}$ binding site at the interface of an interlocked dimer. EMBO J 22: 3210-3219, 2003.

12. Jonsson S, Ricagno S, Lindqvist Y and Richards NG: Kinetic and mechanistic characterization of the formyl-CoA transferase from Oxalobacter formigenes. J Biol Chem 279: 36003-36012, 2004.

13. Quayle JR: Carbon assimilation by Pseudomonas oxalaticus (OX1). 6. Reactions of oxalyl-coenzyme A. Biochem J 87: 368-373, 1963.

14. Demoz A, Garras A, Asiedu DK, Netteland B and Berge RK: Rapid method for the separation and detection of tissue shortchain coenzyme A esters by reversed-phase high-performance liquid chromatography. J Chromatogr B Biomed Appl 667: 148-152, 1995.

15. Allison MJ, Cook HM, Milne DB, Gallagher S and Clayman RV: Oxalate degradation by gastrointestinal bacteria from humans. J Nutr 116: 455-460, 1986.

16. Duncan SH, Richardson AJ, Kaul P, Holmes RP, Allison MJ and Stewart CS: Oxalobacter formigenes and its potential role in human health. Appl Environ Microbiol 68: 3841-3847, 2002.
17. Sidhu H, Enatska L, Ogden S, Williams WN, Allison MJ and Peck AB: Evaluating children in the Ukraine for colonization with the intestinal bacterium Oxalobacter formigenes, using a polymerase chain reaction-based detection system. Mol Diagn 2: 89-97, 1997.

18. Sidhu H, Schmidt ME, Cornelius JG, et al: Direct correlation between hyperoxaluria/oxalate stone disease and the absence of the gastrointestinal tract-dwelling bacterium Oxalobacter formigenes: possible prevention by gut recolonization or enzyme replacement therapy. J Am Soc Nephrol 10 (suppl 14): 334-340, 1999.

19. Kwak C, Kim HK, Kim EC, Choi MS and Kim HH: Urinary oxalate levels and the enteric bacterium Oxalobacter formigenes in patients with calcium oxalate urolithiasis. Eur Urol 44: 475-481, 2003

20. Mittal RD, Kumar R, Mittal B, Prasad R and Bhandari M: Stone composition, metabolic profile and the presence of the gutinhabiting bacterium Oxalobacter formigenes as risk factors for renal stone formation. Med Princ Pract 12: 208-213, 2003.

21. Mittal RD, Kumar R, Bid HK and Mittal B: Effect of antibiotics on Oxalobacter formigenes colonization of human gastrointestinal tract. J Endourol 19: 102-106, 2005.

22. Ruan ZS, Anantharam V, Crawford IT, et al: Identification, purification, and reconstitution of OxlT, the oxalate: formate antiport protein of Oxalobacter formigenes. J Biol Chem 267: 10537-10543, 1992.

23. Lung HY, Cornelius JG and Peck AB: Cloning and expression of the oxalyl-CoA decarboxylase gene from the bacterium, Oxalobacter formigenes: prospects for gene therapy to control Ca-oxalate kidney stone formation. Am J Kidney Dis 17: 381-385, 1991.

24. Lung HY, Baetz AL and Peck AB: Molecular cloning, DNA sequence, and gene expression of the oxalyl-coenzyme A decarboxylase gene, oxc, from the bacterium Oxalobacter formigenes. J Bacteriol 176: 2468-2472, 1994.

25. Sidhu H, Ogden SD, Lung HY, Luttge BG, Baetz AL and Peck AB: DNA sequencing and expression of the formyl coenzyme A transferase gene, frc, from Oxalobacter formigenes. J Bacteriol 179: 3378-3381, 1997.

26. Cormack BP, Valdivia RH and Falkow S: FACS-optimized mutants of the green fluorescent protein (GFP). Gene 173: 33-38, 1996.

27. Zimmer M: Green fluorescent protein (GFP): applications, structure, and related photophysical behavior. Chem Rev 102: 759-781, 2002.

28. Nolan GP, Fiering S, Nicolas JF and Herzenberg LA: Fluorescence-activated cell analysis and sorting of viable mammalian cells based on beta-D-galactosidase activity after transduction of Escherichia coli lacZ. Proc Natl Acad Sci USA 85: 2603-2607, 1988

29. Jimenez A and Davies J: Expression of a transposable antibiotic resistance element in Saccharomyces. Nature 287: 869-871, 1980 . 